\title{
Adherencia bacteriana en los materiales de sutura de uso habitual en cirugía bucal. Revision sistemática.
}

\section{Bacterial aggregation in the suture materials usually used in oral surgery. Systematic review.}

\author{
D. Benito Pedregosa*, E. Jané-Salas**, A. Estrugo-Devesa**, C. Princep Arisó*, J. Moreno \\ Vicente*, A. Marí Roig***, J. López-López****.
}

\section{RESUMEN}

Objetivo: Demostrar la existencia de agregación bacteriana a los materiales de sutura que suelen emplearse en la práctica odontológica, comprobar si dicha agregación está relacionada con la inflamación que sucede al acto quirúrgico y por último dar recomendaciones sobre qué tipo de sutura se adapta mejor para la prevención de la adherencia bacteriana.

Material y método: Búsqueda bibliográfica a través de las bases de datos PubMed, Cochrane y Scielo empleando las palabras clave: surgical sutures, bacterial adherence. Como criterios de inclusión se aceptaron los estudios publicados en los últimos 15 años, in vivo o in vitro en relación con la cirugía oral y con un nivel de evidencia científico superior a 3 según los criterios de evidencia científica. Fueron excluidas todas aquellas publicaciones que no tenían como objeto de estudio las sutura seda, Nylon ${ }^{\mathrm{TM}}$, Supramid ${ }^{\mathrm{TM}}$, Monocryl ${ }^{\mathrm{TM}}$, Vicryl ${ }^{\mathrm{TM}}$ o Vicryl Plus ${ }^{\mathrm{TM}}$. También se excluyeron todas aquellas publicaciones que no relacionaban los materiales de sutura a la agregación bacteriana.

Resultados: Un total de 9 publicaciones se organizaron en función del tipo de sutura empleada, si eran estudios in vivo o in vitro, el número de pacientes/muestras, tiempo transcurrido hasta la remoción de las suturas, si se realizaron controles, si existió algún tipo de reacción inflamatoria, que tipo de bacterias se agregaron y que material obtuvo mayor agregación.

Discusión: Los materiales de sutura que mayor acúmulo de placa bacteriana presentan bajo las mismas condiciones de tiempo de exposición a bacterias, son los de tipo multifilamento reabsorbible no tratados con antimicrobianos.

PALABRAS CLAVE: Surgical sutures AND bacterial adherence; sutures AND bacteria AND oral surgery

* $\quad$ Máster en Medicina, Cirugía e Implantología Oral. Facultad de Medicina y Ciencias de la Salud, Uni versidad de Barcelona.

* * Departamento de Odontoesotmoatología. Facultad de Medicina y Ciencias de la Salud (Odontología), Universidad de Barcelona // Oral Health and Masticatory System Group, Institut d'Investigació Biomédica de Bellvitge (IDIBELL, Bellvitge Institute of Biomedical Research), L'Hospitalet de Llobregat, Barcelona, España.

*** Médico Especialista en Cirugía Oral y Maxilofacial. Jefe de Servicio de Cirugía Maxilofacial. Hospital Universitario de Bellvitge, L'Hospitalet de Llobregat, Barcelona, España // Oral Health and Masticatory System Group, Institut d'Investigació Biomédica de Bellvitge (IDIBELL, Bellvitge Institute of Biomedical Research), L'Hospitalet de Llobregat, Barcelona, España.

**** Departamento de Odontoesotmoatología. Facultad de Medicina y Ciencias de la Salud (Odontología), Universidad de Barcelona // Oral Health and Masticatory System Group, Institut d'Investigació Biomédica de Bellvitge (IDIBELL, Bellvitge Institute of Biomedical Research), L'Hospitalet de Llobregat, Barcelona, España // Director Facultativo y Responsable del Área Médico Quirúrgica del Hospital Odontológico Universidad de Barcelona (HOUB). L'Hospitalet de Llobregat, Barcelona, España. 


\begin{abstract}
Objective: To demonstrate the existence of bacterial aggregation to the suture materials that are usually used in dental practice, to verify if aggregation is related to the inflammation that occurs after the surgical act and finally give recommendations on what type of suture is best suited for the prevention of bacterial adhesion.

Material and method: Bibliographic search through PubMed, Cochrane and Scielo databases using the keywords: surgical sutures, bacterial adherence. Inclusion criteria were accepted studies published in the last 15 years, in vivo or in vitro in relation to oral surgery and with a level of scientific evidence of more than 3 according to the criteria of scientific evidence. All those publications that did not have the suture subject Silk, Nylon ${ }^{\mathrm{TM}}$, Supramid ${ }^{\mathrm{TM}}$, Monocryl ${ }^{\mathrm{TM}}$, Vicryl ${ }^{\mathrm{TM}}$ or Vicryl Plus ${ }^{\mathrm{TM}}$ were excluded. All publications that did not relate suture materials to bacterial aggregation were also excluded.

Results: A total of 9 publications were organized according to the type of suture used, whether they were in vivo or in vitro studies, the number of patients/samples, time elapsed until removal of the sutures, controls if they were performed, any type of inflammatory reaction, which type of bacteria were added and which material obtained greater aggregation. Discussion: The suture materials with the greatest accumulation of bacterial plaque present under the same conditions of exposure to bacteria, are the reabsorbable multifilament type not treated with antimicrobials.
\end{abstract}

KEY WORDS: Surgical sutures AND bacterial adherence; sutures AND bacteria AND oral surgery.

Fecha de recepción: 8 de agosto de 2019

Fecha de aceptación: 5 de septiembre de 2019

D. Benito Pedregosa, E. Jané-Salas, A. Estrugo-Devesa, C. Princep Arisó, J. Moreno Vicente, A. Marí Roig, J. López-López. Adherencia bacteriana en los materiales de sutura de uso habitual en cirugía bucal. Revisión sistemática. 2020; 36, (1): 11-19.

\section{INTRODUCCIÓN}

El término sutura se aplica a cualquier hilo de material utilizado para ligar vasos sanguíneos o aproximar tejidos. Los egipcios y sirios ya utilizaban suturas en el año 2000 a.C. A lo largo de los siglos se han utilizado en procedimientos operatorios muchos materiales distintos, como seda, lino, algodón, crin de caballo, tendones e intestinos de animales y alambres de materiales preciosos ${ }^{(1,2)}$. El objetivo principal de la sutura es iniciar y favorecer el proceso de cicatrización de las heridas, para ello se aproximan sus bordes y cuando esto se ha conseguido, la sutura ha cumplido su objetivo y ya no es necesaria ${ }^{(1)}$.

Según Kudur et al.(3) en 1912, Moynihan describió las condiciones que debería reunir la sutura ideal: I) Acabado monofilamento; II) Fácil manejo; III) Reacción tisular mínima; IV) Resistencia tensil alta; V) Anudado fácil y seguro; VI) Absorbible y con periodo de absorción predecible y estéril. A estas condiciones se añadieron posteriormente las de mínima predisposición a la infección y mínimo efecto memoria ${ }^{(3)}$.

\section{TIPOS DE SUTURA:}

De una manea académica las podemos dividir en:

I.- Por su origen: naturales y sintéticas. Las naturales son aquellas cuyo origen es animal, vegetal o mineral. Las sintéticas son aleaciones de distintos materiales como son las poliamidas, que por medio de diferentes procesos e incluso mediante la nanotecnología se logra obtener un material de sutura ideal y con características adecuadas para todo tipo de tejido ${ }^{(3-5)}$.

II.-Por su morfología: sutura monofilamento o trenzadas. La sutura monofilamento, formadas por una única hebra de material, pasa más fácilmente a través del tejido, dado que el efecto de arrastre es menor, por lo que la reacción tisular se reduce. Sin embargo, debido a su estructura, hay que tener cuidado al manipularlas y anudarlas. El aplastamiento o pinzamiento puede crear muescas o zonas débiles en el hilo, lo que podría provocar su rotura. En cambio, las sutura trenzadas o multifilamento, aquellas que están formadas por varias hebras de material, son más manejables, sobre todo si están recubier- 
tas. Aunque hay que tener en cuenta que pueden provocar una mayor respuesta tisular debido a que su estructura favorece la agregación bacteriana ${ }^{(3-5)}$.

III.-Por su degradación: sutura absorbibles o no absorbibles. La sutura absorbible se degrada en los tejidos por un proceso de hidrólisis, por el que van perdiendo progresivamente la resistencia a la tensión. La degradación por hidrólisis provoca una mínima reacción en los tejidos. Durante la primera etapa, la resistencia a la tensión disminuye de forma gradual. La segunda etapa suele superponerse a la anterior y se caracteriza por la pérdida de masa de sutura. En esta fase se produce respuesta celular leucocitaria que elimina de la herida los restos de células y materiales de la sutura ${ }^{(1,3-5)}$. Por el contrario, la sutura no absorbible está constituidas por material no biodegradable, por lo que no pueden ser digeridas por las enzimas ni hidrolizarse en los tejidos. Aunque ofrecen muchas ventajas, la sutura absorbible también tienen ciertas limitaciones. Si un paciente tiene fiebre o sufre alguna infección o deficiencia de proteínas, el proceso de absorción de la sutura se puede ver acelerado. Además, si las suturas se mojan o humedecen durante la manipulación previa a su uso, la absorción puede comenzar de forma prematura. Todas estas situaciones predisponen a complicaciones postoperatorias ${ }^{(1,3-5)}$.

Por otro lado, si nos centramos en las suturas más frecuentemente utilizadas en cirugía oral, podemos referirnos a (Tabla 1 ):

Tabla 1. Clasificación y ejemplos de sutura más frecuentemente utilizadas en cirugía oral.

\begin{tabular}{|c|c|c|c|c|}
\hline & Composición & $\begin{array}{l}\text { Reabsorbible/ } \\
\text { No reabsorbible }\end{array}$ & Tipo sutura & Origen \\
\hline Nylon $^{\mathrm{TM}}$ & Poliamida 6,6 & No reabsorbible & Monofilamento & Sintética \\
\hline Supramid ${ }^{\mathrm{TM}}$ & Poliamida 6 & No reabsorbible & Trenzado & Sintética \\
\hline Vicryl $^{\mathrm{TM}}$ & Poliglactina 910 & Reabsorbible & Trenzado & Sintética \\
\hline Vicryl PLus $^{\mathrm{TM}}$ & $\begin{array}{l}\text { Poliglactina } 910 \\
\text { Tratada con triclosán }\end{array}$ & Reabsorbible & Trenzado & Sintética \\
\hline Monocryl $^{\mathrm{TM}}$ & Poliglecaprona 25 & Reabsorbible & Monofilamento & Sintética \\
\hline Seda & $\begin{array}{l}\text { Fibra proteica derivada } \\
\text { del gusano de seda }\end{array}$ & No reabsorbible & Trenzado & Natural \\
\hline
\end{tabular}

a.-Poliamidas. Nylon $^{\mathrm{TM}}$ y Supramid ${ }^{\mathrm{TM}}$ ). Nylon ${ }^{\mathrm{TM}}$ es monofilamento y Supramid ${ }^{\mathrm{TM}}$ es pseudomonofilamento (multifilamento hasta el calibre 5/0 y monofilamento a partir de 6/0). Es una poliamida sintética con bajo coeficiente de fricción, gran fuerza de tensión y plasticidad, reacción inflamatoria mínima y no facilita el crecimiento bacteriano. Esto evita dejar marcas de sutura, pero favorece que corte los bor- des de la herida. Otros inconvenientes son la rigidez, que dificulta su manejo y la poca seguridad de los nudos. Puede tardar en absorberse hasta 2 años ${ }^{(3,5)}$.

b.- Poliglactina 910. (Vicryl $^{\mathrm{TM}}$ ) Multifilamento hasta calibre 8/0, monofilamento en calibre 9-10/0. Se reabsorbe en 70-90 días. Está compuesto por polímeros de ácido glicólico y láctico. El recubrimiento es una combinación 50/50 de copolímero de lactato-glicolato (poliglactina 370) y estearato cálcico. El estearato cálcico está compuesto de calcio y ácido esteárico, dos sustancias presentes en el organismo que son fácilmente metabolizadas y excretadas por la orina. Estas características dotan su recubrimiento de una óptima capacidad de absorción, adherencia y suavidad. Tiene gran fuerza de tensión y seguridad del nudo. A las 2 semanas mantiene un $65 \%$ de la fuerza de tensión y a las 3 semanas el $40 \%{ }^{(3,5)}$.

c.- Poliglecaprona 25 (Monocryl $^{\mathrm{TM}}$ ). Monofilamento 6/0, se reabsorbe en 90-120 días. Se utiliza en suturas intradérmicas e hipodérmicas. Induce menos cicatrices hipertróficas que el poliglicano de absorción rápida y menor fuerza de tensión ya que a la semana pierde el $50 \%$ y a las 2 semanas solo mantiene el $25 \%$ de la fuerza de tensión del primer día ${ }^{(3,5)}$.

d.-Seda. Multifilamento. Procede de la fibra proteica natural extraída de la larva del gusano de seda. Es la sutura más utilizada en cirugía por la seguridad del nudo, fácil manejo y por no cortar los bordes de la herida. Aunque se considera no absorbible, puede absorberse en 2 años. Está revestida de silicona y parafina para crear una superficie más lisa y uniforme. Sus inconvenientes son la escasa fuerza de tensión, la poca elasticidad, la reacción celular inflamatoria y la infección bacteriana ${ }^{(3,5)}$.

La cavidad oral está expuesta a todo tipo de bacterias. Dicha exposición tiene repercusión durante el proceso de cicatrización de las heridas ${ }^{(3)}$. Para tener en cuenta que tipo de bacterias son las que tienen mayor predilección en la adherencia a los materiales de sutura hay que distinguirlas en función de sus características entre bacterias aerobias, bacterias anaerobias y por último anaerobios facultativos. Una definición funcional de los anaerobios es que necesitan una reducción de la presión parcial de oxígeno para proliferar. Estas bacterias son microorganismos patógenos frecuentes. A me- 
nudo las bacterias que son anaerobios facultativos se denominan "aerobios"(6,7).

Cuando suturamos una herida hay que tener presente que estamos aplicando un material en un medio muy colonizado por bacterias. Si tenemos en cuenta que para el organismo la sutura es un cuerpo extraño y que puede provocar reacción inflamatoria en la zona tratada; al sumarle la alta carga bacteriana que rodea este medio y que intentará colonizar el material de sutura utilizado; obtendremos finalmente, una situación poco favorable para una correcta cicatrización y posibilidad de infección ${ }^{(7,8)}$.

El objetivo de este trabajo es revisar la evidencia o no de agregación bacteriana a los materiales de sutura que suelen emplearse en odontología tras una intervención quirúrgica. Analizar (en caso de existir) si dicha agregación está relacionada con la inflamación que ocurre después del acto quirúrgico y por último establecer conclusiones sobre cuál debería ser el tipo de sutura a emplear en la práctica clínica.

\section{MATERIAL Y MÉTODOS}

Se realizó una búsqueda bibliográfica por DBP, AES y CPA a través de la base de datos PubMed/Medline, Scielo y Cochrane, empleando las palabras clave: surgical sutures AND bacterial adherence; sutures AND bacteria AND oral surgery. Los trabajos encontrados y una vez consensuados, son revisados por EJS y JMV y los desacuerdos son valorados por AMR y JLL.

Como criterios de inclusión se aceptaron los estudios publicados en los últimos 15 años, en humanos, in vivo o in vitro en relación con la cirugía oral, estudios comparativos en lengua inglesa y estudios con un nivel de evidencia científico superior a 3 según los criterios de evidencia científica de la Agencia para la Investigación y Calidad de la Atención Médica del Centre for Evidence-Based Medicine de la Agency for Healthcare Research and Quality, en la que se evalúa la calidad general de la investigación médica en un campo determinado según la escala de Jadad. Fueron excluidas todas aquellas publicaciones que no tenían como objeto de estudio las sutura que consideramos, bajo nuestro propio criterio clínico, que son las más utilizadas en la práctica diaria: seda, Nylon ${ }^{\mathrm{TM}}$, Supramid ${ }^{\mathrm{TM}}$, Monocryl ${ }^{\mathrm{TM}}$, Vicryl ${ }^{\mathrm{TM}}$ y Vicryl Plus ${ }^{\mathrm{TM}}$. También se excluyeron todas aquellas publicacio- nes que no relacionaban los materiales de sutura con la agregación o el acúmulo de bacterias.

\section{RESULTADOS}

En la base de datos PubMed, con la primera búsqueda se obtuvieron como resultado 35 publicaciones, de las cuales se excluyeron 21 en base a los criterios de exclusión. Obteniendo un total de 4 publicaciones. Con las palabras clave "sutures AND bacteria AND oral surgery" se encontraron 17 publicaciones, de las cuales, tras aplicar los criterios de exclusión, obtuvimos un total de 2 publicaciones. De las descartadas, 10 publicaciones coincidían con las publicaciones obtenidas en la búsqueda de "surgical sutures AND bacterial adherence". A través de la base de datos Scielo, utilizando las palabras clave "sutures" englobando todos los índices de búsqueda (palabras en el título, autor, materia, resumen, año de publicación e idioma original) se obtuvieron como resultado un total de 23 publicaciones; de las cuales, tras aplicar los criterios de exclusión nos quedamos con 2. A través de la base de datos Cochrane, utilizando las palabras clave "surgical sutures $A N D$ bacteria AND Oral surgery" se obtuvieron como resultado 10 publicaciones (9 ensayos clínicos y una revisión sistemática). De las 10 publicaciones encontradas 6 fueron excluidas en base a los criterios de inclusión establecidos. Los 3 restantes eran repetidos de la base de datos PubMed, que habíamos seleccionado previamente ${ }^{(8-10)}$. Una revisión sistemática fue excluida bajo los criterios de inclusión establecidos dado que se estudiaba el efecto de un antibiótico para la prevención de la infección ${ }^{(6)}$. Del total de publicaciones seleccionadas, se excluyeron 3 publicaciones debido a que no cumplían con el nivel de evidencia no inferior a 3. Finalmente nos quedamos con 9 publicaciones (Figura 1): 2 ensayos clínicos controlados aleatorizados con un nivel de evidencia de 3 [Banche et al. 2007(8); Galal and El-Hindawy 2011(11)]. 5 casos-control con un nivel de evidencia de 4 [Masini, Stinner, Waterman and Wenke $2011^{(7)}$; de Castro Costa Neto et al. 2014(12); Meghil et al. 2015(13); Matalon et al. $2013^{(14)}$ y Venema et al. $2010^{(15)}$ y 2 estudios de cohortes de tipo prospectivo [Pons-Vicente, Lopez-Jimenez, et al. 2010 ${ }^{(9)}$; Pelz and Tödtmann $2015^{(15)}$ ] con un nivel de evidencia de 3 . En la Tabla 1, se presentan los resultados más significativos de los 9 trabajos revisados que incluyen 6 tipos de sutura diferentes. 
D. Benito Pedregosa, E. Jané-Salas, A. Estrugo-Devesa, C. Princep Arisó, J. Moreno Vicente, A. Marí Roig, J. López-López. Adherencia bacteriana en los materiales de sutura de uso habitual en cirugía bucal. Revision sistemática.

Los diferentes trabajos se organizaron en función del tipo de sutura empleada, si eran estudios in vivo o in vitro, el número de pacientes/muestras, cuanto tiempo transcurrió antes de la remoción de las suturas, si se realizaron controles o no y en caso de realizarlos cual fue la frecuencia, si existió algún tipo de reacción en los tejidos a lo largo del tiempo, si hubo agregación bacteriana o no y qué tipo de bacterias se agregaron (en caso de producirse) y que material obtuvo mayor agregación (Tablas 2,3).
Todos los estudios compararon bacterias presentes en la cavidad oral. La adherencia del Fusobacterium nucleatum, Prevotella intermedia y streptococcus fue estudiada en 3 artículos ${ }^{(8,9,14)}$. La bacteria que más presencia tuvo en las publicaciones seleccionadas, con un total de 4) fue el Staphylococcus aureus ${ }^{(7,8,14,15)}$. Enterococcus y Actinobacillus fueron objeto de estudio en 2 publicaciones cada uno ${ }^{(10,13)}$; y por último la bacteria Escherichia Coli y el hongo Candida Albicans fueron estudia-

\begin{tabular}{|c|c|c|c|c|c|c|c|c|}
\hline Artículos & Tipo sutura & $\begin{array}{l}\text { In vivo/ } \\
\text { In vitro }\end{array}$ & $\begin{array}{l}\text { Número } \\
\text { pacientes }\end{array}$ & $\begin{array}{l}\text { Remoción } \\
\text { suturas }\end{array}$ & Controles & $\begin{array}{l}\text { Reacción } \\
\text { tejidos }\end{array}$ & Bacterias en estudio & Adherencia bacteriana \\
\hline $\begin{array}{l}\text { Pelz E } \\
\text { Tödtmann } \\
2015 \text { (15) }\end{array}$ & $\begin{array}{l}\text { Vicryl }^{\mathrm{TM}} \\
\text { Vicryl PLus }^{\mathrm{TM}} \\
\mathbf{4 / 0}\end{array}$ & In vivo & 17 & 7 días & - & - & $\begin{array}{l}\text { Aerobios } \\
\text { Aggregatibacter } \\
\text { actinomycetemcomitans } \\
\text { Actinomyces naeslundii } \\
\text { Anaerobios } \\
\text { Prevotella intermedia, } \\
\text { Parvimonas micra } \\
\text { Peptostreptococcus micros } \\
\text { Fusobacterium nucleatum }\end{array}$ & $\begin{array}{l}\text { No hay diferencias } \\
\text { significativas, no } \\
\text { recomiendan uso } \\
\text { de Vicryl Plus }^{\mathrm{TM}}\end{array}$ \\
\hline $\begin{array}{l}\text { Pons-Vicente } \\
\text { et al. } 2010 \text { (9) }\end{array}$ & $\begin{array}{l}\text { Seda } \\
\text { PTFE Teflon }{ }^{\mathrm{TM}} \\
\mathbf{3} / \mathbf{0}\end{array}$ & In vivo & 10 & 7 días & - & - & $\begin{array}{l}\text { Enterococcus faecalis, } \\
\text { Escherichia coli and } \\
\text { Streptococcus mutans + } \\
\text { hongo candida albican }\end{array}$ & $\begin{array}{l}\text { ․ E. coli y } \\
\text { E. faecalis }\end{array}$ \\
\hline $\begin{array}{l}\text { Banche } \\
\text { et al. } 2007 \text { (8) }\end{array}$ & $\begin{array}{l}\text { Supramid } \\
\text { Monocryl }^{\mathrm{TM}} \\
\text { Ethibond excel }^{\mathrm{TM}} \\
\text { Synthofil }^{\mathrm{TM}} \\
\text { Ti.cron } \\
\text { Seda (control) }\end{array}$ & In vivo & 60 & 8 días & $\begin{array}{l}\text { A las } 3 \\
\text { semanas } \\
\text { tras retirar } \\
\text { suturas }\end{array}$ & $\begin{array}{l}\text { Sin signos } \\
\text { de infección } \\
\text { en los dos } \\
\text { controles }\end{array}$ & $\begin{array}{l}\text { Streptococcus } \\
\text { Staphylococcus } \\
\text { Actinomyces Pasteurella } \\
\text { Veillonella parvula, } \\
\text { Peptostreptococcus, } \\
\text { Actinobacillus, Prevotella } \\
\text { Fusobacterium }\end{array}$ & $\begin{array}{l}\text { >Anaerobios }(2 / 1) \\
\text { < en reabsorbible } \\
\left(\text { Monocryl }^{\mathrm{TM}}\right)\end{array}$ \\
\hline $\begin{array}{l}\text { Galal E } \\
\text { El-Hindawy } \\
2011(11)\end{array}$ & $\begin{array}{l}\text { Vicryl }^{\mathrm{TM}} \\
\text { Vicryl PLus }^{\mathrm{TM}}\end{array}$ & In vivo & 450 & ? & 30 días & $\begin{array}{l}\text { Proceso infec- } \\
\text { cioso en } 50 \text { de } \\
\text { los pacientes } \\
(12,5 \%)\end{array}$ & - & $\begin{array}{l}\text { Vicryl PLus }{ }^{\mathrm{TM}} \\
\text { Presenta menor inci- } \\
\text { dencia de infección } \\
\text { postoperatoria }\end{array}$ \\
\hline Artículos & Tipo sutura & $\begin{array}{l}\text { Iln vivo/ } \\
\text { In vitro }\end{array}$ & $\begin{array}{l}\text { Número } \\
\text { pacientes }\end{array}$ & $\begin{array}{l}\text { Remoción } \\
\text { suturas }\end{array}$ & Controles & $\begin{array}{l}\text { Reacción } \\
\text { tejidos }\end{array}$ & Bacterias en estudio & Adherencia bacteriana \\
\hline $\begin{array}{l}\text { Massini et al. } \\
2011 \text { (7) }\end{array}$ & $\begin{array}{l}\text { Vicryl }{ }^{\mathrm{TM}} \\
\text { Vicryl PLus }^{\mathrm{TM}} \\
\text { Monocryl }^{\mathrm{TM}} \\
\text { Prolene } \\
\text { Seda } \\
2 / 0\end{array}$ & In vitro & - & 48 horas & - & - & Staphylococcus aureus & $>$ Vicryl $^{\mathrm{TM}}$ \\
\hline $\begin{array}{l}\text { Venema et al. } \\
2010(15)\end{array}$ & $\begin{array}{l}\text { Vicryl }{ }^{\mathrm{TM}} \\
\text { Vicryl PLus }^{\mathrm{TM}} \\
\mathbf{3 / 0}\end{array}$ & In vitro & $\begin{array}{l}\text { Saliva } \\
\text { de } 28 \\
\text { pacientes }\end{array}$ & 7 días & - & - & $\begin{array}{l}\text { Streptococcus sanguis } \\
\text { S. aureus }\end{array}$ & $\begin{array}{l}\text { NO hay diferencias } \\
\text { significativas. } \\
\text { Vicryl PLus } \\
\text { Contraindicado si } \\
\text { se emplean agentes } \\
\text { antibacterianos }\end{array}$ \\
\hline $\begin{array}{l}\text { de Castro } \\
\text { Costa Neto et } \\
\text { al. } 2014 \text { (12) }\end{array}$ & $\begin{array}{l}\text { Nylon }^{\mathrm{TM}} \\
\text { Seda } \\
\text { Vicryl }^{\mathrm{TM}} \\
\text { Vicryl PLus }^{\mathrm{TM}}\end{array}$ & In vitro & - & 5 días & - & - & $\begin{array}{l}\text { Prevotella intermedia } \\
\text { Y Fusobacterium } \\
\text { nucleatum }\end{array}$ & $\begin{array}{l}>\text { Fusobacterium N. } \\
<\text { Nylon }^{\mathrm{TM}} \\
\text { y Vicryl PLus }\end{array}$ \\
\hline $\begin{array}{l}\text { Meghil et al. } \\
2015 \text { (13) }\end{array}$ & $\begin{array}{l}\text { Nylon }^{\mathrm{TM}} \\
\text { Seda } \\
\text { Poliéster } \\
\text { Impregnados en } \\
\text { QAC K21 }\end{array}$ & In vitro & - & 12 días & - & - & $\begin{array}{l}\text { Porphyromonas gingivalis } \\
\text { Enterococcus faecalis }\end{array}$ & $\begin{array}{l}<\text { Respecto a las } \\
\text { suturas control }\end{array}$ \\
\hline $\begin{array}{l}\text { Matalon et al. } \\
2013(14)\end{array}$ & $\begin{array}{l}\text { Vicryl PLus } \\
\text { Seda } \\
\text { Poliester } \\
\text { Catgut }\end{array}$ & In vitro & - & 2 y7 días & - & - & $\begin{array}{l}\text { S. aureus } \\
\text { S. epidermidis } \\
\text { P. aeruginosa }\end{array}$ & $\begin{array}{l}<\text { Vicryl PLus }{ }^{\mathrm{TM}} \\
\text { Para S. Aureus y } \\
\text { epidermidis }\end{array}$ \\
\hline
\end{tabular}


dos en una única publicación ${ }^{(9)}$.

Los materiales de sutura más estudiados en esta revisión fueron la seda (Perma-Hand ${ }^{\mathrm{TM}}$, Ethicon. Inc.) $(7-9,12,14)$ y el Vycril Plus ${ }^{\mathrm{TM}}$, Ethicon, Inc, (Somerville, New Jersey $)^{(7,10-12,14,15)}$ (6 publicaciones cada uno). Seguidamente el Vycril ${ }^{\mathrm{TM}}$, Ethicon, Inc, (Somerville, New Jersey) ${ }^{(7,10-12,15)}$ (5 publicaciones); el Monocril $^{\mathrm{TM}}$, Ethicon, Inc, (Somerville, New Jersey) $)^{(7,8)}$ y el Nylon (Ethilon) ${ }^{(12,13)}$ (2 cada una) y finalmente el Supramid ${ }^{\mathrm{TM}}$, (B. Braun, Melsungen, Germany) $)^{(8)}$, con una publicación.

En 4 de los 9 artículos seleccionados se llevaron a cabo estudios in vivo(8-11). La remoción de las suturas se llevó a cabo en 7 días en 3 estudios $^{(9,10,15)}$; en dos estudios en 8-12 días ${ }^{(8,13)}$, mientras que en el resto osciló entre 2 y 7 días. Únicamente en un estudio retiraron las suturas en $12 h^{(7)}$ y en otro no se especifica si se retiran las suturas o no ${ }^{(11)}$. Dos estudios llevaron a cabo controles de los tejidos una vez retiradas las suturas [a las 3 semanas $^{(8)}$ y a los 30 días $^{(11)}$ ], en ambos se observó algún tipo de reacción inflamatoria (Tablas 2,3).

Para analizar y calcular la agregación bacteriana, en el estudio de Masini et al. (2011) ${ }^{(7)}$, las hebras de las suturas fueron analizadas mediante la captura de imágenes con un sistema de cámara de fotones que produce un recuento total de fotones que se correlaciona con la cantidad de bacterias residual. Por el contrario, Banche et al. $(2007)^{(8)}$ prepararon disoluciones en serie ( $\mathrm{NaCl}$ al $0,9 \%)$, de modo que se pudiera determinar el número de unidades formadoras de colonias (ufc/ml). Se colocaron en placa $100 \mu l$ de cada disolución en Agar y en varios medios adecuados para bacterias aeróbicas y anaeróbicas. Para cuantificar el número total anaerobios estrictos gramnegativos, colocaron muestras durante 2 a 4 días a $37^{\circ} \mathrm{C}$ en condiciones aeróbicas para bacterias aerobias y levaduras, bajo un 5\% - 10\% de dióxido de carbono (CO2) para bacterias aerobias / anaerobias facultativas, y durante 5 a 9 días a $37^{\circ} \mathrm{C}$ bajo condiciones estrictamente anaeróbicas para bacterias anaerobias obligadas y facultativas. Después de la incubación, se registró el número de ufc/ml.

De Castro Costa Neto et al. (2014)(12); Meghil et al. $(2015)^{(13)}$ y Venema et al. (2010)(15) analizaron las muestras mediante microscopía electrónica de barrido (SEM) con un voltaje de $15 \mathrm{kv}$, a 1000 aumentos. Pons-Vicente et al. (2010) ${ }^{(9)}$ inocularon medios de cultivo selectivos para detectar microorganismos
Tabla 4: Resultados de la comparación de

diferentes materiales de sutura "in vitro" e "in vivo".

Adherencia bacteriana

Estudios in vivo -Menor adherencia bacteriana en monofilamentos (Monocryl $^{\mathrm{TM}}$ )

- Vycril $^{\mathrm{TM}}$ y Vycril Plus ${ }^{\mathrm{TM}}$ no hay diferencias significativas. -Mayor adherencia bacteriana de anaerobios

Estudios in vitro -Menor adherencia bacteriana en Nylon ${ }^{\mathrm{TM}}$ y Vycril Plus ${ }^{\mathrm{TM}}$ - Mayor adherencia bacteriana en Vycril $^{\mathrm{TM}}$ -Mayor adherencia bacteriana anaerobios (Fusobacterium Nucleatum)

utilizando una unidad de formación de colonias por unidad de área de superficie (ufc/superficie). Pelz and Tödtmann $(2015)^{(10)}$ y Matalon et al. (2013) (14) realizaron tinción de Gram y determinaron las morfologías celulares mediante microscopía óptica. Finalmente, Galal and El-Hindawy $(2011)^{(11)}$ determinaron la agregación bacteriana en función de los signos de inflamación y el nivel de placa acumulado en las suturas (Tablas 2,3,4).

Si nos centramos más detalladamente podemos observar que:

Massini et al. (2011)(7) llevan a cabo un estudio in vitro comparativo entre Vicryl ${ }^{\mathrm{TM}}$, Vicryl Plus ${ }^{\mathrm{TM}}$, Monocryl $^{\mathrm{TM}}$, Prolene ${ }^{\mathrm{TM}}$, y seda, donde la remoción de la sutura se realizó a las 12 horas y obtuvieron como resultados una mayor agregación bacteriana por parte de Staphylococcus aureus en Vicryl ${ }^{\mathrm{TM}}$.

Banche et al. (2007)(8) llevan a cabo un estudio in vivo comparativo entre Supramid ${ }^{\mathrm{TM}}$, Monocryl ${ }^{\mathrm{TM}}$, Ethibond Excel $^{\mathrm{TM}}$, Synthofil ${ }^{\mathrm{TM}}$ y Ti-cron ${ }^{\mathrm{TM}}$ con la seda como material control, con una muestra de 60 pacientes, remoción de la sutura a los 8 días y control posterior a las 3 semanas donde ningún paciente presenta infección. Las bacterias sometidas a estudio fueron Streptococcus, Staphylococcus, Actinomyces, Pasteurella, Veillonella parvula, Peptostreptococcus, Actinobacillus, Prevotella y Fusobacterium. Los resultados dieron una agregación bacteriana superior de anaerobios (2/1) y el material con menor agregación fue Monocryl ${ }^{\mathrm{TM}}$.

De Castro Costa Neto et al. (2014) ${ }^{(12)}$ presentan un estudio in vitro comparativo entre los materiales de sutura Nylon $^{\mathrm{TM}}$, seda, Vicryl ${ }^{\mathrm{TM}}$ y Vicryl Plus $^{\mathrm{TM}}$. La retirada de la sutura fue tras un período de 5 días de cultivo frente a las bacterias Prevotella intermedia y Fusobacterium nucleatum. Los resultados presentaban al Nylon ${ }^{\mathrm{TM}}$ y el Vicryl Plus $^{\mathrm{TM}}$ como los materiales que menor agregación bacteriana tenían y que esta estaba principalmen- 
te formada por Fusobacterium nucleatum.

Meghil et al. (2015)(13) estudiaron in vitro los materiales de sutura Nylon ${ }^{\mathrm{TM}}$, seda y poliéster impregnados en un antibacteriano (QAC K21). La retirada de la sutura fue a los 12 días de incubación frente a las bacterias Porphyromonas gingivalis y Enterococcus faecalis. Los resultados fueron que las suturas impregnadas ofrecían menor índice de agregación bacteriana que las sutura control.

Pons-Vicente et al. (2010) ${ }^{(9)}$ llevaron a cabo un estudio in vivo comparativo en 10 pacientes entre los materiales de sutura seda y PTFE Teflon ${ }^{\mathrm{TM}}$. La retirada de la sutura fue a los 7 días, no se realizaron más controles y ningún paciente mostro signos de infección. Las bacterias analizadas fueron Enterococcus faecalis, Escherichia coli y Streptococcus mutans + hongo Candida albicans. Los resultados fueron positivos a las bacterias Enterococcus faecalis y Escherichia coli como las más predominantes.

Pelz and Tödtmann (2015)(10) llevaron a cabo un estudio in vivo comparativo con una muestra de 17 pacientes y donde tenían como objeto de estudio los materiales de sutura Vicryl ${ }^{\mathrm{TM}}$ y Vicryl Plus $^{\mathrm{TM}}$. La retirada de la sutura fue a los 7 días, sin más controles y sin presentar ningún paciente signos de reacción tisular. Las bacterias a estudio fueron Aggregatibacter actinomycetemcomitans, Actinomyces naeslundii, Prevotella intermedia, Parvimonas micra, Peptostreptococcus micros y Fusobacterium nucleatum. Los resultados no mostraron diferencias significativas entre la agregación bacteriana de los distintos materiales.

Matalon et al. (2013) $)^{(14)}$ estudiaron in vitro la agregación bacteriana de S. aureus, S. epidermidis y $P$. Eruginosa a los materiales de sutura Vicryl Plus ${ }^{\mathrm{TM}}$, seda, poliéster y Catgut. La retirada de la sutura fue entre los 2 y 7 días y los resultados presentaban al Vicryl Plus ${ }^{\mathrm{TM}}$ como el material que menor agregación bacteriana sufría y las bacterias $\mathrm{S}$. aureus y $S$. epidermidis como las más predominantes.

Venema et al. (2010)(15) presenta un estudio in vitro donde comparan la agregación bacteriana de Streptococcus sanguis y $S$. aureus a los materiales de sutura Vicryl ${ }^{\mathrm{TM}}$ y Vicryl Plus ${ }^{\mathrm{TM}}$. Este estudio tenía como objeto de muestra la saliva de 28 pacientes. Las suturas fueron retiradas a los 7 días y los resultados fueron que no existen diferencias significativas entre ambos materiales de sutura. Desaconsejan el uso de Vicryl Plus ${ }^{\mathrm{TM}}$ en caso de recomendar en las instrucciones postquirúrgicas el uso de colutorios antimicrobianos.

Galal and El-Hindawy (2011) $)^{(11)}$ presenta un estudio in vivo con una muestra de 450 pacientes donde estudiaron qué material (Vicryl ${ }^{\mathrm{TM}}$ y Vicryl Plus ${ }^{\mathrm{TM}}$ ) presentaba menor infección postoperatoria. Tras un control a lo largo de 30 días, 50 de los pacientes presentó algún tipo de proceso infeccioso en la zona quirúrgica (12,5\%). Los resultados situaban al Vicryl Plus $^{\mathrm{TM}}$ como el material que menor reacción tisular postoperatoria presentaba.

\section{DISCUSIÓN}

Según Massini et al. (2011) ${ }^{(7)}$ ante la presencia de Staphylococcus aureus, a lo largo de un periodo de incubación de $12 \mathrm{~h}$ en condiciones in vitro, el Vicryl ${ }^{\mathrm{TM}}$, es la sutura que mayor adherencia bacteriana presenta por delante de la seda, el Monocry $\mathrm{l}^{\mathrm{TM}}$ y Vicryl Plus $^{\mathrm{TM}}$ respectivamente. Estos resultados coinciden con los estudios de Galal \& El-Hindawy (2011)(11) donde se sitúa al Vicryl ${ }^{\mathrm{TM}}$ como la sutura que mayor índice de adherencia bacteriana presenta comparado con Vicryl Plus ${ }^{\mathrm{TM}}$ tratado con triclosán. Massini et al. $(2011)^{(7)}$ sitúan la seda como el segundo material de sutura en cuanto a mayor adherencia bacteriana se refiere. Estos datos coinciden con los resultados obtenidos por Banche et al. (2007) ${ }^{(8)}$ que concluyen que el Monocryl ${ }^{\mathrm{TM}}$ presenta menor agregación bacteriana que la seda tras un periodo de incubación bacteriana de 3 semanas en condiciones in vivo. No, así como el Supramid ${ }^{\mathrm{TM}}$ que, según los resultados, presenta mayor agregación bacteriana comparada con la seda. De Castro Costa Neto et al. (2014) ${ }^{(12)}$ obtienen que la seda presenta mayor número de agregación bacteriana seguida muy de cerca por el Vicry $^{\mathrm{TM}}$. Matalon et al. (2013)(14) también citan a la seda como el material que sufre mayor agregación bacteriana in vitro en 7 días, aunque en este caso la comparación se hace con Vicryl Plus ${ }^{\mathrm{TM}}$ (tratado con triclosán 2,2,4-trichloro-2-hydroxy-diphenyl ether en una concentración de $150 \mathrm{mg} / \mathrm{m})$. Meghil et al. $(2015)^{(13)}$, al igual que Matalon et al. (2013) $)^{(14)}$ obtienen como resultados que la seda acumula mayor carga bacteriana; en su estudio la comparación se da con Nylon ${ }^{\mathrm{TM}}$, en condiciones in vitro a lo largo de 12 días. Pero en este caso los materiales de sutura están tratados con un antimicrobiano, aun y así, dado que ambos materiales están en las mismas condiciones de ser tratados los resultados son extra- 
polables. El estudio del Pons-Vicente et al. (2010) (9) en condiciones in vivo durante 10 días, concluyen que la seda presenta mayor carga bacteriana comparada con el monofilamento politetrafluoruro de etileno. Pelz and Tödtmann (2015) ${ }^{(10)}$ y Venema et al. (2010) (15) no encuentran diferencias significativas entre Vicryl $^{\mathrm{TM}}$ y Vicryl Plus ${ }^{\mathrm{TM}}$.

Pese a que la comparación de materiales de sutura se realiza entre materiales reabsorbibles y no reabsorbibles, los resultados que se han obtenido, es teniendo en cuenta que la remoción de las suturas se produce al mismo tiempo en todos ellos. Habría que tener en cuenta que tanto el Vicryl ${ }^{\mathrm{TM}}$ como Vicryl plus $^{\mathrm{TM}}$ están fabricados para ser reabsorbidos sin necesidad de remoción, esta reabsorción tal y como se ha comentado anteriormente oscila entre los 6090 días, con lo cual el acúmulo de carga bacteriana sería mayor comparado con el resto que suelen ser removidos en un lapso de tiempo entre 7 y 21 días (depende del protocolo según proceso quirúrgico que se haya realizado). Por lo que tras analizar los resultados podemos observar cómo tanto Vicryl Plus $^{\mathrm{TM}}$ como Nylon $^{\mathrm{TM}}$ ofrecen los mejores índices en cuanto a menor agregación bacteriana, seguidos del Monocryl $^{\mathrm{TM}}$ y dejando la seda y el Vicryl ${ }^{\mathrm{TM}}$ como los que presentan mayor acúmulo de bacterias. Hay que tener en cuenta a la hora de analizar los resultados, que los materiales de sutura más estudiados en los artículos seleccionados fueron la seda y el Vicryl Plus $^{\mathrm{TM}}$ (6 publicaciones cada uno), seguidos por el Vicryl $^{\mathrm{TM}(5)}$, el Monocryl ${ }^{\mathrm{TM}}$ y el Nylon ${ }^{\mathrm{TM}}$ (2 cada una) y el Supramid ${ }^{\mathrm{TM}(1)}$. Por lo que harían falta más estudios comparativos y si es posible a boca partida para poder obtener conclusiones; al igual que no se especifica en ninguno de ellos si los pacientes utilizaron agentes microbianos tópicos en el postoperatorio, lo que podría alterar los resultados obtenidos.

Hay que tener presente que el hecho de aplicar un material de sutura provocará una reacción tisular a cuerpo extraño, por lo que el tipo de material jugará un papel muy importante a la hora de la cicatrización de la herida $(16,17)$. Las suturas sintéticas reabsorbibles tienen un menor grado de reacción tisular que las naturales reabsorbibles. Por otro lado, el material de sutura, con la tensión que provoca sobre el lecho de la herida, genera un coeficiente de fricción (mayor o menor roce que produce la sutura al desplazarse en los tejidos), por lo tanto, generará mayor o menor trauma en forma proporcional( ${ }^{16,17)}$. Monofilamento: menor coeficiente de fricción; Multifilamento: mayor co- eficiente, sintéticas menor que naturales.

La mayoría de las bacterias que se adhieren a los materiales de sutura son de tipo anaerobio y anaerobios facultativos (Banche et al. 2007 ${ }^{(8)}$, De Castro Costa Neto et al. 2014(12), Matalon et al. 2013 (14), Pons-Vicente et al. $(2010)^{(9)}$; si bien, aunque Pelz and Tödtmann $(2015)^{(10)}$ presentan resultados sin diferencias significativas al respecto.

En cuanto a la presencia de signos de inflamación y de infección tras remover las suturas a los 8 días, Banche et al. (2007) ${ }^{(8)}$ no detectan signos inflamatorios mientras que en el estudio in vivo de Galal and El-Hindawy $(2011)^{(11)}$, tras realizar un control de los pacientes a los 30 días (no retiraron las suturas dado que analizaban los materiales reabsorbibles Vicryl ${ }^{\mathrm{TM}}$ y Vicryl Plus ${ }^{\mathrm{TM}}$ ), observaron signos de inflamación en 50 de los 450 pacientes evaluados. Lo que representa aproximadamente que el 12,5\% de la muestra desarrolló infección de la zona tratada. Una posible explicación a estos datos podría ser debido a que está demostrado que cuanto mayor es el tiempo que dejamos un material a cuerpo extraño en boca, como serían los materiales de sutura, mayor es el acúmulo de placa y carga bacteriana que se acumula. Un estudio que evalúa este dato, es el estudio de Galal and El-Hindawy $(2011)^{(11)}$, se realizaron controles a lo largo de 30 días, durante los cuales va aumentando la carga bacteriana en el material de sutura, lo que puede acabar dando lugar a infecciones tardías ${ }^{(16,18)}$.

\section{CONCLUSIÓN}

Los materiales de sutura que mayor acúmulo de placa bacteriana presentan bajo las mismas condiciones de tiempo de exposición a bacterias, son los de tipo multifilamento reabsorbible no tratados con antimicrobianos, seguidos muy de cerca por los multifilamentos no reabsorbibles.

El material de sutura reabsorbible presenta una mayor adherencia bacteriana comparado con el no reabsorbible. Así como los materiales monofilamentos ofrecen una menor adherencia bacteriana que los multifilamentos.

Durante el tiempo que permanezca el material de sutura en boca, se le ha de indicar al paciente que siga como pautas de higiene oral, limpiar la zona quirúrgica y aplicar algún agente antimicrobiano. 
D. Benito Pedregosa, E. Jané-Salas, A. Estrugo-Devesa, C. Princep Arisó, J. Moreno Vicente, A. Marí Roig, J. López-López. Adherencia bacteriana en los materiales de sutura de uso habitual en cirugía bucal. Revision sistemática.

Como limitaciones de nuestro estudio cabe destacar que este trabajo podría ampliarse y establecer una relación entre los materiales de sutura que menor carga bacteriana acumulan y la resistencia a la tensión de cada uno de ellos; obteniendo así el tiempo idóneo para retirar las suturas.

\section{BIBLIOGRAFIA}

1) Brandt $M T$ T. Suturing Principles for the Dentoalveolar Surgeon. Dent Clin N 2012; 56: 281-303.

2) Mackenzie D. The history of sutures. Med Hist 1973; 17: 158-68.

3) Kudur MH, Pai SB, Sripathi H, Prabhu S. Sutures and suturing techniques in skin closure. Indian $\mathrm{J}$ Dermatol Venereol Leprol 2009; 75: 425-34.

4) Meyle J. Suture Materials and Suture Techniques. Perio 2006; 3(4): 253-68.

5) Armas Moredo K, Bárbaro A, Segura Pujal L. Surgical suture materials. AMC 2009; 13. versión On-line ISSN 1025-0255.

6) Heal CF, Banks JL, Lepper PD, Kontopantelis $E$, van Driel ML. Topical antibiotics for preventing surgical site infection in wounds healing by primary intention. Cochrane Database Syst Rev 2016; 11: CD011426.

7) Masini, B, Stinner, DM, Waterman S, Wenke, J. Bacterial Adherence to Suture Materials. Journal of surgical education. J Surg Educ 2011; 68:101-4.

8) Banche G, Janira R, Narcisa M, Mario A, Cesare G, Valeria A, et al. J Oral Maxillofac Surg 2007; 65: 1503-7.

9) Pons-Vicente O, Lopez-Jimenez L, Sanchez-Garces M.A, Sala-Perez S, Gay-Escoda C.

A comparative study between two different suture materials in oral implantology. Clin Oral Implants Res 2011; 22: 282-8.

10) Pelz K, Tödtmann N. Comparison of antibacterial-coated and non-coated suture material in intraoral surgery by isolation of adherent bacteria. Ann Agric Environ Med 2015; 22(3):551-5.
11) Galal I, El-Hindawy K. Impact of using triclosan-antibacterial sutures on incidence of surgical site infection. Am J Surg 2011; 202 (Pt 2): 133-8.

12) de Castro Costa Neto O, Araujo Lobo L, Lopes Pontes Iorio N, Carvalho Vasconcelos M, Cople Maia L, Nivoloni Tannure P, et al. Oral bacteria adherence to suture threads: an in vitro study. Oral Maxillofac Surg 2015; 19: 275-80.

13) Meghil M, Rueggeberg F, El-Awady A, Miles B, Tay F, Pashley D, Cutler C. Novel Coating of Surgical Suture Confers Antimicrobial Activity Against Porphyromonas gingivalis and Enterococcus faecalis. J Periodontol 2015; 86 (6): 788-94.

14) Matalon S, Kozlovsky A, Kfir A, Weiss EI, Levartovsky S, Mazor Y, Slutzky H. The effect of commonly used sutures on inflammation inducing pathogens An in vitro study. J Craniomaxillofac Surg. 2013; 41 (Pt 7): 593-7.

15) Venema S, Abbas F, van de Belt-Gritter B, van der Mei $\mathrm{H}$, van der ouderaa F, Busscher HJ, van Hoogmoed CG. In vitro oral biofilm formation on triclosan-coated sutures in the absence and presence of additional antiplaque treatment. J Oral Maxillofac Surg 2011; 69(4): 980-5.

16) Bucci M, Borgonovo A, Bianchi A, Zanellato A, Re D. Microbiological analysis of bacterial plaque on three different threads in oral surgery. Minerva Stomatol 2017; 66(1): 28-34.

17) Rino $B$, Niklaus $P$. Influence of suturing on wound healing. Periodontol 2000 2015; 68(1): 270-81.

18) Asher R, Chacartchi T, Tandlich $M$, Shapira L, Polak D. Microbial accumulation on different suture materials following oral surgery: a randomized controlled study. Clin Oral Investig 2019; 23(2):559-65.

\section{CORRESPONDENCIA:}

José López López

Facultad de Medicina y Ciencias de la Salud

(Odontología), Universidad de Barcelona

Campus Universitario de Bellvitge

Pabellón de Gobierno

C/ Feixa LLarga s/n 08907

L'Hospitalet de Llobregat Barcelona - España

18575jll@gmail.com 